\title{
INCORPORAÇÃO DE RESÍDUO DE LÃ DE VIDRO EM CONCRETO
}

\author{
Paulo Roberto Borges ' \\ Eduardo Junca ${ }^{2}$ \\ Felipe Fardin Grillo ${ }^{3}$ \\ Victor Bridi Telles ${ }^{4}$ \\ José Roberto de Oliveira ${ }^{5}$ \\ Jorge Alberto Soares Tenório ${ }^{4}$
}

\section{Resumo}

A incorporação de resíduos em substituição aos agregados em concreto têm sido uma alternativa na obtenção de novas rotas para disposição de resíduos. Assim, o objetivo deste trabalho é estudar a incorporação de resíduo de lã de vidro em concreto por duas rotas. Na primeira, o resíduo foi moído para ser incorporado. Na segunda, o resíduo foi incorporado como recebido, sem nenhum tratamento. A caracterização do resíduo foi realizada na amostra moída através análise química, difração de raios- $X$, análise granulométrica e microscópio eletrônico de varredura acoplado com EDS. A porcentagem de resíduo de lã de vidro no concreto variou em $2,5 \%, 5,0 \%, 7,5 \%$ e $10,0 \%$ para ambos os testes. Os resultados mostraram que para incorporação de $2,5 \%$ de resíduo no concreto ocorreu uma diminuição na resistência mecânica de apenas 3,1\% com 28 dias de cura. Assim, a incorporações do resíduo de lã de vidro em concreto pode ser uma alternativa para a sua disposição final. Entretanto, o teor de adição do mesmo deve ser estimado de acordo com a resistência mecânica final exigida do concreto.

Palavras-chave: Resíduo de lã de vidro; Resíduo sólido; Concreto.

\section{INCORPORATION OF GLASS WOOL WASTE IN CONCRETE}

\begin{abstract}
The incorporation of wastes to replace the aggregates into concrete has been an alternate to create new routes to disposal it. In this way, the aim of this paper is to study the incorporation of glass wool waste into concrete. The incorporation was performed in two routes. In the first, the waste was milled to be incorporated. The second, the waste was incorporated as-received into concrete. The characterization was performed in the milled waste by chemical analysis, X-ray diffraction, size analysis and scanning electrons microscopy coupled with EDS spectrum. The waste content into the concrete was 2.5, 5.0, 7.5 and $10 \mathrm{wt} \%$ in both tests. The results indicate that incorporation of $2.5 \%$ of waste decreased the strength resistance in around $3.1 \%$ at 28 -days curing. Thus, incorporation of glass wool waste into concrete can be an alternative to its disposal. However, the waste content into concrete should be estimated according to the final strength resistance required by concrete.
\end{abstract}

Keywords: Glass wool waste; Solid waste; Concrete.

\footnotetext{
'Instituto Federal de Educação, Ciências e Tecnologia de Ouro Preto - IFMG, Ouro Preto, MG, Brasil.

${ }^{2}$ Programa de Pós-graduação em Ciência e Engenharia de Materiais, Universidade do Extremo Sul Catarinense - UNESC, Criciúma, SC, Brasil. E-mail: eduardojunca@unesc.net

${ }^{3}$ Programa de Pós-graduação em Ciência e Engenharia de Materiais, Universidade do Extremo Sul Catarinense - UNESC, Criciúma, SC, Brasil.

${ }^{4}$ Departamento de Engenharia Química, Universidade de São Paulo - USP, São Paulo, SP, Brasil.

${ }^{5}$ Departamento de Metalurgia e Materiais, Instituto Federal de Educação, Ciências e Tecnologia do Estado do Espírito Santo - IFES,

Vitória, ES, Brasil.
}

2176-1523 (C) 2017 Associação Brasileira de Metalurgia, Materiais e Mineração. Publicado pela ABM. Este é um artigo de acesso aberto distribuído sob os termos da licença Creative Commons CC BY-NC-ND (Attribution-NonCommercial-NoDerivs) - https:// creativecommons.org/licenses/by-nc-nd/4.0\%. 


\section{INTRODUÇÃO}

A lã de vidro é um importante material usado em diversos setores industriais, tais como metalúrgico, químicos e em utensílios domésticos devido a suas propriedades térmicas e acústicas [I,2]. Entretanto, quando estas propriedades são perdidas, este material é descartado, geralmente, em aterros. De acordo com Evangelista et al. [3], o resíduo de lã de vidro é classificado como classe II-A, perigosos e não inertes pela norma NBR 10.004 , podendo ser descartado em aterros industriais classe II.

O tratamento de resíduo sólido pode ser realizado por vários métodos tais como: químicos, biológicos, térmicos e físicos. Destes, o tratamento físico tem atraído atenção, uma vez que envolve métodos simples e mais baratos. Dentre os métodos de tratamento físico, o emprego de resíduos no setor de construção civil tem atraído pesquisadores de toda parte do mundo [4-6] visto que, os agregados tradicionais do concreto poderem ser substituídos por resíduo [7]. Exemplo deste tipo de estudos é trabalho desenvolvido por Zamora et al. [8], onde o autor incorporou o lodo de água de bebidas em concreto. De acordo com o autor, a incorporação do lodo aumentou a resistência a compressão do concreto quando se adicionou $75 \%$ de lodo. Para Lima e Zulanas [9], a incorporação de aproximadamente $5 \%$ de lodo em concreto apresentou um aspecto positivo no que diz respeito ao meio ambiente, visto que diminuiu a quantidade destinada para os aterros. Entretanto, a incorporação de resíduos em concreto não deve comprometer as propriedades mecânicas e ambientais do concreto. Monte [ 10$]$ investigou - uso de fibras de polipropileno e aço em concretos. A autora observou que concretos fabricados com fibra de polipropileno apresentou menor resistência mecânica uma vez que a fibra de polipropileno possuir uma menor resistência quando comparada às fibras de aço.

Estes exemplos mostram que a incorporação de resíduos em concretos é uma prática realizada por diversos pesquisadores. Entretanto, cada resíduo apresenta sua característica especifica, o que leva a necessidade de uma investigação do comportamento do mesmo quando adicionado ao concreto. Neste contexto, 0 objetivo deste trabalho é investigar a incorporação de resíduo de lá de vidro em concreto visando criar uma nova alternativa para a disposição do resíduo, o que pode se tornar uma alternativa para diminuir o volume de aterro ocupado, além de diminuir a quantidade explorada de fontes de materiais primas naturais.

\section{MATERIAIS E MÉTODOS}

\section{I Matérias-Primas}

O resíduo de lã de vidro utilizado nos testes é procedente de um aterro localizado no estado do Espírito Santo. Foram coletados cerca de $200 \mathrm{~kg}$ de resíduo para realização de todos os testes. A incorporação do resíduo no concreto foi realizada de duas maneiras. Na primeira, 0 resíduo de lã de vidro foi moído com auxílio de um moinho de bolas visando fragmentar o mesmo para incorpora-lo no concreto. Este resíduo moído foi caracterizado via análise química, microscópio eletrônico de varredura acoplado com microssonda EDS, difração de raios-X e análise granulométrica. No segundo, o resíduo foi manualmente desagregado visando sua incorporação no concreto.

A areia usada na elaboração do concreto foi classificada de acordo com a norma ABNT NBR 72II/2005 [II]. Em adição, a massa especifica foi também determinada via norma ABNT NBR 9776/2004 [12]. O agregado graúdo é procedente de rocha granítica e sua classificação se deu de acordo com as normas ABNT NBR NM 248/2003 [13] e NBR 72 I I/2005 [ I I]. Como aglomerante, foi utilizado o cimento Portland CPIII. Este cimento apresentou como principais características área específica de $400 \mathrm{~m}^{2} / \mathrm{kg}$ e massa especifica de $2,97 \mathrm{~kg} / \mathrm{dm}^{3}$.

\subsection{Preparação do Concreto}

Duas misturas foram elaboradas para confecção de concreto. Para a primeira, o resíduo de lã de vidro foi moído por um moinho de bola para ser incorporado no concreto. No segundo, o resíduo de lã de vidro foi desagregado manualmente para ser incorporado ao concreto. Em ambos os casos, o concreto foi dosado com cimento, areia, agregado grosso e água na proporção de I:2,83:3,7:0,7l, respectivamente. Este traço foi adotado uma vez que é a principal composição de concreto utilizada na grande Vitória-Brasil para obter $16 \mathrm{MPa}$ de resistência a compressão após 28 dias de cura. Além disso, o resíduo de lã de vidro foi adicionado ao concreto visando substituir a massa de cimento, como pode ser observado na Tabela I.

As amostras nomeadas PS foram aquelas contendo resíduo de lã de vidro moído, enquanto que as amostras nomeadas NS são aquelas com adição de lã de vidro manualmente desagregada. O número em cada abreviação indica a porcentagem de resíduo de lã de vidro adicionada em relação à massa total do concreto. A amostra nomeada como Referência foi confeccionada sem adição de resíduo com o intuído de comparar a variação da resistência à compressão do concreto contendo resíduo incorporado. Com relação à preparação das misturas e corpos de prova, esta etapa foi realizada de acordo com a norma NBR I2.82 I/1993 [14].

\subsection{Slump Teste}

O slump teste foi realizado visando investigar a trabalhabilidade do concreto em cada composição. Este teste seguiu a norma NBR NM 67//998 [15].

\subsection{Resistencia a Compressão}

Os testes de resistência a compressão foram realizados de acordo com a norma NBR 5739/1994 [16]. Este teste foi realizado para comparar a resistência a compressão 
uniaxial obtidas para 3, 7 e 28 dias de cura. Utilizou-se uma prensa de compressão da marca Servo EMIC acoplada a um computador para coleta de dados. Os valores de resistência a compressão final foram calculados a partir da média aritmética obtida nos cinco testes para cada composição.

\section{RESULTADOS E DISCUSSÃO}

\section{I Caracterização do Resíduo de Lã de Vidro}

A composição química do resíduo de lã de vidro (Tabela 2) mostra que o principal componente é o $\mathrm{SiO}_{2}$ (45,39\%). Também foram determinados $16,21 \%$ de $\mathrm{CaO}$, $12,76 \%$ de $\mathrm{Al}_{2} \mathrm{O}_{3}$ e $12,37 \%$ de $\mathrm{Fe}_{2} \mathrm{O}_{3}$. Outros elementos também foram detectados, tais como $\mathrm{MgO}(7,01 \%), \mathrm{TiO}_{2}$
(2,82\%), $\mathrm{Na}_{2} \mathrm{O}(2,09 \%), \mathrm{K}_{2} \mathrm{O}(0,88 \%), \mathrm{P}_{2} \mathrm{O}_{5}(0,25 \%), \mathrm{MnO}$ $(0,19)$ e $\mathrm{ZrO}_{2}(0,03 \%)$.

A imagem obtida por microscópio eletrônico de varredura (Figura IA) mostra o aspecto morfológico do resíduo de lã de vidro após a etapa de moagem. A imagem indica que a maior parte das partículas são menores que $100 \mu \mathrm{m}$. O espectro de EDS (Figura IB) mostra a composição química pontual do resíduo moído, no qual indica a presença $\mathrm{de} \mathrm{Fe}, \mathrm{Si}, \mathrm{Ca}, \mathrm{Al}, \mathrm{O}$ e Ti. Este resultado sustenta os resultados obtidos pela análise química, que indicou estes elementos como sendo os principais constituintes do resíduo.

A análise granulométrica (Tabela 3 ) indica que o resíduo de lã de vidro após etapa de cominuição apresentou $87,18 \%$ das partículas menores que $0,1 \mathrm{~mm}$, sendo $70,04 \%$

Tabela I. Proporção das massas dos componentes utilizados na formulação do concreto

\begin{tabular}{|c|c|c|c|c|c|}
\hline Amostra & Resíduo de lã de vidro (kg) & Cimento (kg) & Areia (kg) & Agregado graúdo (kg) & Água (kg) \\
\hline Referencia & 0 & 9,587 & 27,171 & 35,452 & 7,312 \\
\hline PS-2,5 & 0,24 & 9,347 & 27,171 & 35,452 & 7,312 \\
\hline PS-5,0 & 0,479 & 9,107 & 27,171 & 35,452 & 7,312 \\
\hline PS-7,5 & 0,719 & 8,868 & 27,171 & 35,452 & 7,312 \\
\hline PS-10,0 & 0,959 & 8,628 & $27,17 \mid$ & 35,452 & 7,312 \\
\hline NS-2,5 & 0,24 & 9,347 & 27,171 & 35,452 & 7,312 \\
\hline NS-5,0 & 0,479 & 9,107 & $27,|7|$ & 35,452 & 7,312 \\
\hline NS-7,5 & 0,719 & 8,868 & 27,171 & 35,452 & 7,312 \\
\hline NS-10,0 & 0,959 & 8,628 & 27,171 & 35,452 & 7,312 \\
\hline
\end{tabular}

Tabela 2. Composição química do resíduo de lã de vidro

\begin{tabular}{cccccccccccc}
\hline Elementos & $\mathrm{SiO}_{2}$ & $\mathbf{C a O}$ & $\mathbf{A l}_{2} \mathbf{O}_{3}$ & $\mathbf{F e}_{2} \mathbf{O}_{3}$ & $\mathbf{M g O}$ & $\mathrm{TiO}_{2}$ & $\mathbf{N a}_{2} \mathbf{O}$ & $\mathbf{K}_{2} \mathbf{O}$ & $\mathbf{P}_{2} \mathbf{O}_{5}$ & $\mathbf{M n O}_{2}$ & $\mathrm{ZrO}_{2}$ \\
\hline Porcentagem (\%) & 45,39 & $16,2 \mathrm{I}$ & 12,76 & 12,37 & $7,0 \mathrm{I}$ & 2,82 & 2,09 & 0,88 & 0,25 & 0,19 & 0,03 \\
\hline
\end{tabular}
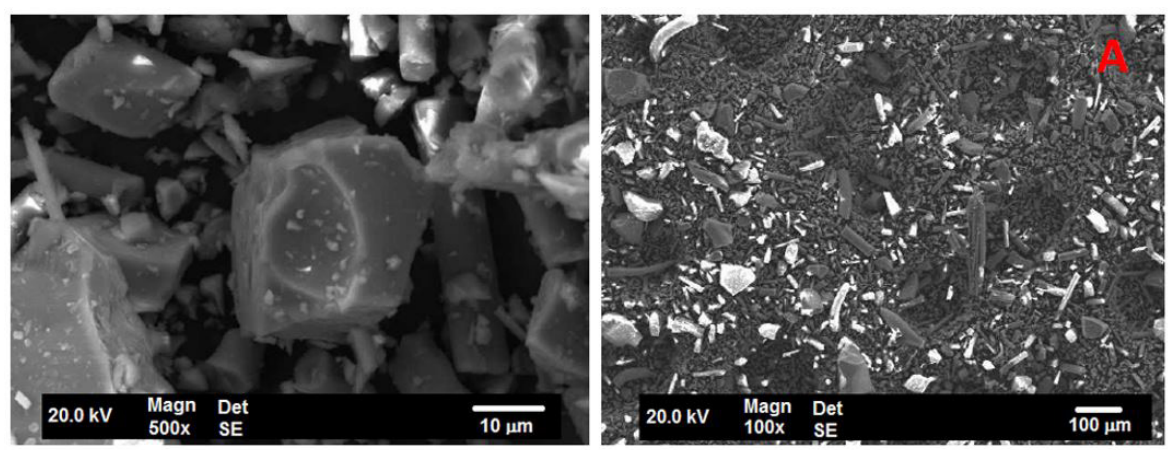

B

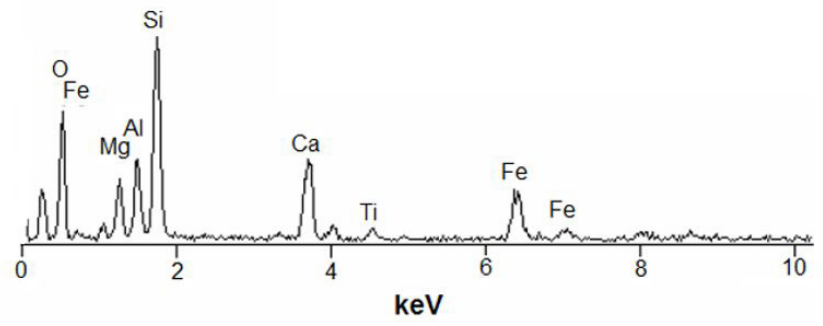

Figura I. (A) Imagem obtido por elétrons secundários através de microscópio eletrônico de varredura do resíduo de lã de vidro. (B) Espectro de EDS da lã de vidro. 
Tabela 3. Análise granulométrica do resíduo de lã de vidro moído

\begin{tabular}{ccc}
\hline Abertura $(\mathbf{m m})$ & Massa retida (g) & Acumulado (\%) \\
\hline 0,21 & 0,00 & 0,00 \\
0,15 & 8,94 & 4,47 \\
0,1 & 16,71 & 12,82 \\
0,07 & 33,05 & 29,35 \\
0,05 & 140,09 & 99,39 \\
0,04 & 0,94 & 99,86 \\
$<0,04$ & 0,27 & 100,00 \\
\hline
\end{tabular}

das partículas situadas entre 0,07-0,05 mm, confirmando os resultados obtidos por microscopia eletrônica de varredura.

A análise de difração de raios-X (Figura 2 ) sugere que o resíduo de lã de vidro é constituído por uma estrutura amorfa, uma vez que o espectro não apresentou picos de cristalinidade.

\subsection{Caracterização dos Componentes do Concreto}

A análise granulométrica da areia (Tabela 4) indicou que $100 \%$ das partículas são menores que $6,3 \mathrm{~mm}$. Em adição, somente $0,75 \%$ das partículas é menor que $0,15 \mathrm{~mm}$. A análise também indicou que a areia apresentou uma faixa granulométrica entre a zona ótima inferior e a superior, como pode ser visto na Figura 3 . O modulo de finura de 2,63 e massa especifica de 2,618 kg/dm também foram determinados.

A Tabela 5 mostra o resultado da análise granulométrica do agregado graúdo utilizado na confecção do concreto. O agregado graúdo apresentou $100 \%$ das partículas menores que 25,4 mm. Além disso, apresentou I,48\% das partículas mais fina que $6,3 \mathrm{~mm}$. Também foi determinado que 54,56\% do agregado graúdo esta compreendido na faixa entre I 2,7-19, I mm. A massa especifica obtida foi de 2,47 kg/ $\mathrm{dm}^{3}$.

\subsection{Incorporação do Resíduo de Lã de Vidro no Concreto}

As Tabelas 6, 7 e 8 mostram os resultados obtidos nos testes de resistência a compressão dos concretos fabricados com adição de resíduo de lã de vidro para tempo de cura de 3, 7 e 28 dias, respectivamente.

Foi notado que a adição de resíduo de lã de vidro no concreto diminuiu a resistência a compressão do mesmo. Para 3 dias de cura a resistência a compressão do concreto diminuiu de 7,94 $\mathrm{MPa}$ (concreto de referência) para 7,14,6,49,5,26 e 4,6I MPa para adições de 2,5, 5,0, 7,5 e 10\% de resíduo de lã de vidro, respectivamente.

Os resultados de resistência mecânica para 7 dias de cura indicaram a mesma tendência, ou seja, aumentando a porcentagem de resíduo no concreto ocorreu uma diminuição da resistência mecânica do mesmo, em torno de 28,6\%.

Os testes para concretos com 28 dias de cura indicaram uma resistência a compressão de $16,68 \mathrm{MPa}$ para o concreto
Tabela 4. Análise granulométrica da areia utilizada na confecção do concreto

\begin{tabular}{ccc}
\hline Abertura (mm) & Massa retida $(\mathbf{g})$ & Acumulado (\%) \\
\hline 9,5 & 0,00 & 0,00 \\
6,3 & 0,00 & 0,00 \\
4,8 & 0,68 & 0,14 \\
2,4 & 12,33 & 2,60 \\
1,2 & 88,82 & 20,37 \\
0,6 & 151,70 & 50,71 \\
0,3 & 193,65 & 89,45 \\
0,15 & 49,00 & 99,25 \\
$<0,15$ & 3,74 & 100 \\
\hline
\end{tabular}

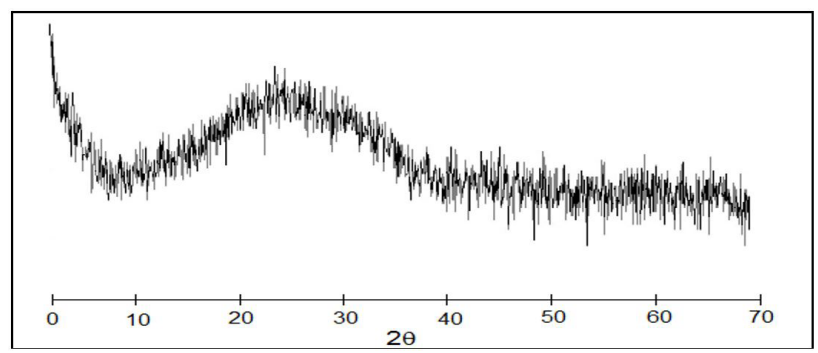

Figura 2. Padrão de difração de raios-X obtidos do resíduo de lã de vidro.

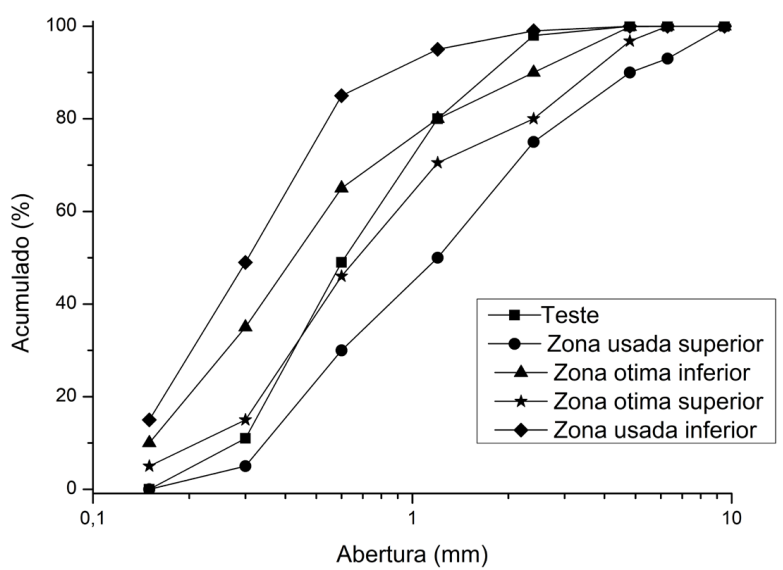

Figura 3. Curva granulométrica obtida do agregado fino (areia) usado na manufatura do concreto.

Tabela 5. Análise granulométrica do agregado graúdo utilizado para confecção do concreto

\begin{tabular}{ccc}
\hline Abertura (mm) & Massa retida (g) & Acumulado (\%) \\
\hline 25,4 & 0,00 & 0,00 \\
19,1 & 115,11 & 2,30 \\
12,7 & 2727,15 & 56,86 \\
9,5 & 1603,57 & 88,94 \\
6,3 & 479,19 & 98,52 \\
$<6,3$ & 73,85 & 100,00 \\
\hline
\end{tabular}

de referência. As amostras contendo 2,5, 5,0, 7,5 e 10\% de resíduo apresentaram resistência a compressão de $16,16,13,7,13,27$ e 12,47 MPa, respectivamente, sugerindo uma queda na resistência a compressão de até $25 \%$. 
O fato de a adição de resíduo ter atuado de modo a diminuir a resistência mecânica do concreto está relacionado diretamente ao aparecimento de descontinuidades na matriz do concreto, o que implica em um maior volume de poros, e consequentemente, uma menor resistência compressão. Tal fato será melhor investigado em item subsequente. Além disso, devido à baixa resistência mecânica apresentado pelo resíduo de lã de vidro, este pode atuar como defeitos na matriz do concreto, o que também leva a um decréscimo na resistência mecânica do concreto $[10,17]$.

Com o objetivo de comparar a resistência a compressão obtidos em todos os testes, a Figura 4 faz uma compilação de todos os resultados.

Foi notado que a substituição do cimento por $2,5 \%$ de resíduo de lã de vidro apresentou resultados similares de resistência a compressão comparando-se com o concreto de referência para 3, 7 e 28 dias de cura. Isto indica a possibilidade da incorporação deste resíduo em concreto como uma alternativa à sua disposição. Da mesma maneira, a resistência a compressão para substituição de cimento por resíduo de lã de vidro como

Tabela 6. Resistencia a compressão do concreto de referência e com adição de resíduo de lã de vidro para 3 dias de cura

\begin{tabular}{|c|c|c|c|c|c|c|c|}
\hline \multirow{2}{*}{$\begin{array}{l}\text { Amostra } \\
\text { Referência }\end{array}$} & \multicolumn{5}{|c|}{$\begin{array}{c}\text { Resistencia a compressão } \\
\text { (MPa) }\end{array}$} & \multirow{2}{*}{$\begin{array}{c}\text { Média } \\
\text { (MPa) }\end{array}$} & \multirow{2}{*}{$\begin{array}{c}\begin{array}{c}\text { Desvio } \\
\text { padrão }\end{array} \\
0,2\end{array}$} \\
\hline & 7,0 & 7,7 & 8,1 & 8,1 & 8,0 & & \\
\hline PS-2,5 & 7,2 & 7,0 & 7,3 & 6,8 & 7,5 & 7,14 & 0,27 \\
\hline PS-5,0 & 6,8 & 5,8 & 6,1 & 6,6 & 6,5 & 6,49 & 0,28 \\
\hline PS-7,5 & 5,3 & 5,4 & 5,1 & 5,8 & 6,0 & 5,26 & 0,17 \\
\hline PS-10 & 4,4 & 4,7 & 4,6 & 4,5 & 4,7 & 4,61 & 0,14 \\
\hline
\end{tabular}

Tabela 7. Resistencia a compressão do concreto de referência e com adição de resíduo de lã de vidro para 7 dias de cura

\begin{tabular}{|c|c|c|c|c|c|c|c|}
\hline \multirow{2}{*}{$\begin{array}{l}\text { Amostra } \\
\text { Referência }\end{array}$} & \multicolumn{5}{|c|}{$\begin{array}{c}\text { Resistencia a compressão } \\
(\mathrm{MPa})\end{array}$} & \multirow{2}{*}{$\begin{array}{c}\text { Média } \\
(\mathrm{MPa})\end{array}$} & \multirow{2}{*}{$\begin{array}{c}\begin{array}{c}\text { Desvio } \\
\text { padrão }\end{array} \\
0,42\end{array}$} \\
\hline & 11,0 & 10,3 & 11,8 & 11,6 & 11,0 & & \\
\hline PS-2,5 & 11,7 & 9,9 & 10,6 & 11,3 & 11,3 & 11,23 & 0,46 \\
\hline PS-5,0 & 9,2 & 8,7 & 8,4 & 9,2 & 9,9 & 8,87 & 0,37 \\
\hline PS-7,5 & 9,0 & 9,2 & 9,0 & 9,6 & 9,3 & 9,22 & 0,25 \\
\hline PS- 10 & 9,1 & 8,2 & 8,4 & 8,0 & 7,8 & 8,09 & 0,25 \\
\hline
\end{tabular}

Tabela 8. Resistencia a compressão do concreto de referência e com adição de resíduo de lã de vidro para 28 dias de cura

\begin{tabular}{cccccccc}
\hline Amostra & \multicolumn{3}{c}{ Resistencia a compressão } & & $\begin{array}{r}\text { Média } \\
(\mathbf{M P a})\end{array}$ & $\begin{array}{c}\text { Desvio } \\
\text { padrão }\end{array}$ \\
\hline Referência & 13,9 & 16,1 & 18,4 & 16,5 & 17,5 & 16,68 & 0,72 \\
PS-2,5 & 17,5 & 15,8 & 16,2 & 16,5 & 18,3 & 16,16 & 0,38 \\
PS-5,0 & 12,5 & 15,2 & 13,5 & 13,6 & 14,0 & 13,70 & 0,24 \\
PS-7,5 & 13,1 & 13,2 & 12,6 & 14,1 & 13,4 & 13,27 & 0,55 \\
PS-10 & 12,7 & 12,4 & 12,8 & 11,8 & 12,8 & 12,47 & 0,43 \\
\hline
\end{tabular}

recebido (Tabela 9) indica uma diminuição da resistência a compressão quando se aumenta o teor de resíduo no concreto. Além disso, a Figura 5 sugere que para substituições acima de $5 \%$ a trabalhabilidade é zero, o que impossibilita a confecção de concreto com estas composições. Além disso, a ausência de trabalhabilidade impossibilitou a determinação da resistência a compressão para estes corpos de provas.

A trabalhabilidade do concreto de referência apresentou um valor de slump teste de $35 \mathrm{~mm}$, enquanto que as outras misturas apresentaram maiores valores para o slump teste, o que indica uma menor trabalhabilidade. Isto indica que o resíduo de lã de vidro diminui a trabalhabilidade do concreto, o que pode restringir o seu uso.

\subsection{Densidade Específica}

A densidade específica (Figura 6) foi determinado para investigar a relação entre a porosidade do concreto e o teor de resíduo de lã de vidro adicionado.

A densidade específica para a amostra de referência foi de $2,354 \mathrm{~kg} / \mathrm{dm}^{3}$. Para as misturas confeccionadas com

Tabela 9. Resistência à compressão das diferentes misturas de concreto contendo resíduo de lã de vidro como recebido

\begin{tabular}{lccccc}
\hline & $\begin{array}{c}\text { Referência } \\
(\mathbf{M P a})\end{array}$ & $\begin{array}{c}\text { NS-2,5 } \\
\mathbf{( M P a})\end{array}$ & $\begin{array}{c}\text { NS-5,0 } \\
(\mathbf{M P a})\end{array}$ & $\begin{array}{c}\text { NS-7,5 } \\
\mathbf{( M P a )}\end{array}$ & $\begin{array}{c}\text { NS-10 } \\
(\mathbf{M P a})\end{array}$ \\
\hline & 13,9 & 14,2 & 11,4 & - & - \\
& 16,1 & 15,0 & 12,4 & - & - \\
& 18,4 & 14,4 & 12,6 & - & - \\
& 16,5 & 14,9 & 11,9 & - & - \\
Média & 17,5 & 15,1 & 11,3 & - & - \\
Desvio & 16,68 & 14,72 & 11,93 & - & - \\
padrão & 0,72 & 0,4 & 0,6 & - & - \\
\hline
\end{tabular}

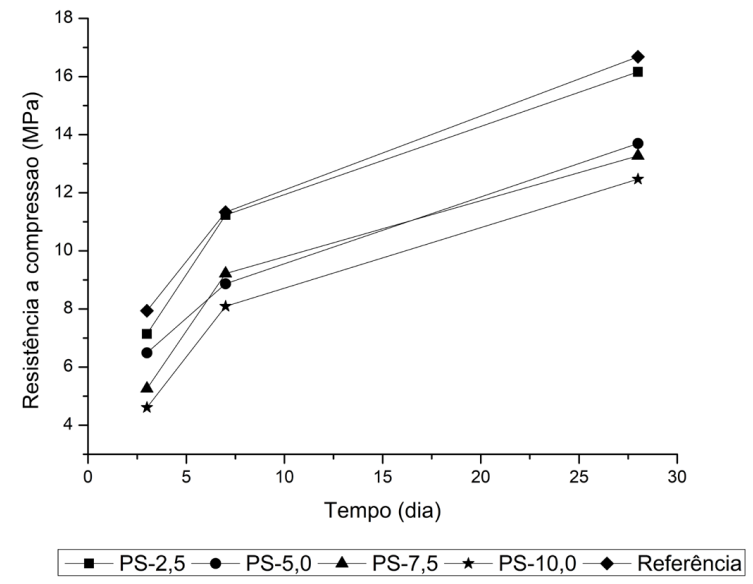

Figura 4. Comparação das resistências a compressão obtidas em 3,7 e 28 dias de cura. 


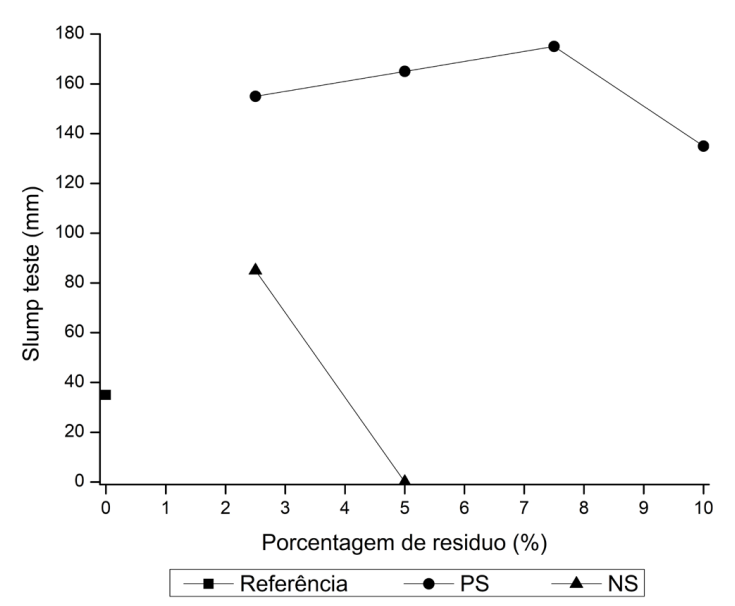

Figura 5. Variação do slump teste com adição de resíduo de lã de vidro em diferentes proporções.

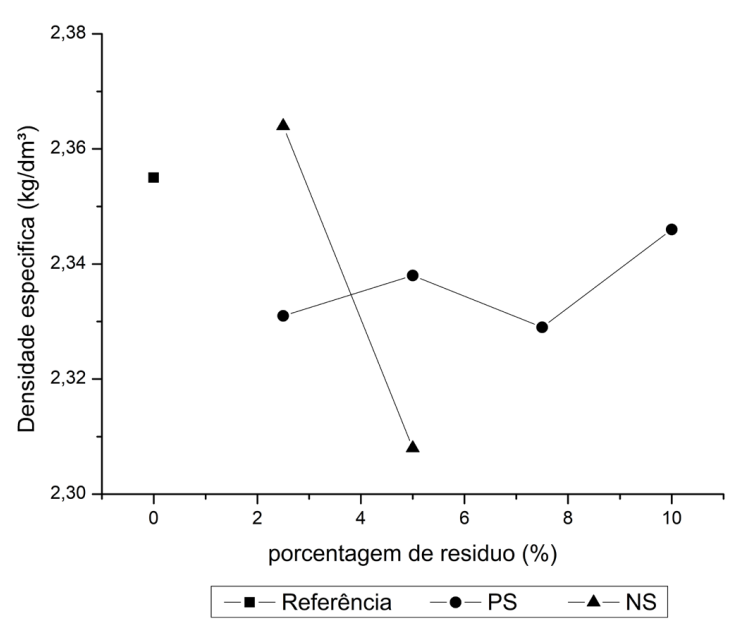

Figura 6. Comparação da densidade específica obtidas nos concretos com adição de resíduo de lã de vidro. resíduo moído apresentou uma diferencia menor que $1 \%$ com relação à mistura de referência. Por outro lado, misturas confeccionadas com resíduo como recebido houve uma diminuição da massa especifica para $2,32 \mathrm{~kg} / \mathrm{dm}^{3}$, o que indica um maior volume de poros dentro do concreto, e por consequência, leva a uma queda na resistência mecânica [ 10$]$.

\section{CONCLUSÃO}

Os estudos apontaram que o resíduo de lã de vidro causou uma diminuição na resistência a compressão dos corpos de provas para todos os teores de adições. Para 3 dias de cura, foi notado uma queda de até $41,9 \%$ na resistência mecânica para adições de até $10 \%$ de resíduo. Para 7 dias de cura, a queda na resistência mecânica chegou a até $28,6 \%$ com $10 \%$ de adição de resíduo. Já para os testes realizados com 28 dias de cura, a perda de resistência mecânica chegou no máximo a $25,2 \%$ para adições de até $10 \%$ de resíduo. Entretanto, para adições de $2,5 \%$ de resíduo, a resistência mecânica do concreto com 28 dias de cura foi de $16,16 \mathrm{MPa}$, indicando uma perda de apenas $3,1 \%$ na resistência mecânica do concreto. Os testes com adições de resíduo de lã de vidro como recebido sugeriram que para teores acima de $5 \%$ de resíduo não houve trabalhabilidade do concreto. Além disso, para adições de $2,5 \%$ de resíduo ocorreu uma perda na resistência mecânica de até II,7\% nos corpos de prova. Desta forma, os resultados mostraram que a adição do resíduo de lã de vidro em concreto pode ser uma alternativa para a sua disposição. Entretanto, o teor de adição do mesmo deve ser estimado de acordo com a resistência mecânica exigida do concreto.

\section{Agradecimentos}

Os autores agradecem ao Instituto Federal de educação, Ciências e Educação do Estado do Espírito Santo e a Universidade do Extremo Sul Catarinense.

\section{REFERÊNCIAS}

I Achchaq F, Djellab K, Beji H. Hydric, morphological and thermo-physical characterization of glass wools: From macroscopic to microscopic approach. Construction \& Building Materials. 2009;23:3214-3219.

2 Tsukamoto M, Murakami T, Yoshimura Y, Kuroki Y, Okamoto T, Takata M. Evaluation of the tensile strength of polypropylene-based composites containing glass wool. Materials Letters. 20I4;132:267-269.

3 Evangelista N, Tenório J A S, Oliveira JR. Pozolanicidade dos resíduos industriais, lã de vidro e lã cerâmica. Revista Escola de Minas. 2012;65:79-85.

4 Pietrobon CLR, Andrade CMG, Colanzi J, Barros IB, Bergamasco R, Pietrobon CE. Lixiviacao de contaminantes de compostos de lodo-cimento. Acta Scientiarum. Technology. 2004;26:45-52.

5 Al-Tulaian BS, Al-Shannag MJ, Al-Hozaimy AR. Recycled plastic waste fibers for reinforcing Portland cement mortar. Construction \& Building Materials. 2016; 127: 102-II0. 
6 Furlani E, Maschio S. Steel scale waste as component in mortars production: an experimental study. Case Studies in Construction Materials. 2016;4:93-101.

7 Fantilli A P, Sicardi S, Dotti F The use of wool as fiber-reinforcement in cement-based mortar. Construction and Building Materials. 2016;139:562-569. http://dx.doi.org/10.1016/j.conbuildmat.2016.10.096.

8 Zamora RMR, Alfaro OC, Cabirol N, Ayala FE, Moreno AD. Valorization of drinking water treatment sludges as raw materials to produce concrete and mortar. American Journal of Environmental Sciences. 2008;4:223-228.

9 Lima DA, Zulanas C. Use of contaminated sludge in concrete. Procedia Engineering. 20 I6; I 45: I 20 I-1 208.

10 Monte R. Caracterização e controle do comportamento mecânico do concreto reforçado com fibras para tubos [tese]. São Paulo: Escola Politécnica, Universidade de São Paulo; 2015.

I I Associação Brasileira de Normas Técnicas. NBR 721 I: Agregado para concreto -Especificação. Rio de Janeiro: ABNT; 2005.

12 Associação Brasileira de Normas Técnicas. NBR 9776: Determinação da massa específica de agregados miúdo por meio do frasco de Chapman. Rio de Janeiro: ABNT; 2004.

13 Associação Brasileira de Normas Técnicas. NBR NM 248: Agregados -Determinação da composição granulométrica. Rio de Janeiro: ABNT; 2003.

14 Associação Brasileira de Normas Técnicas. NBR I282 I: Preparação de concreto em laboratório. Rio de Janeiro: ABNT; 1993.

15 Associação Brasileira de Normas Técnicas. NBR NM 67: Concreto -Determinação da consistência pelo abatimento do tronco de cone. Rio de Janeiro: ABNT; 1998.

16 Associação Brasileira de Normas Técnicas. NBR 5739: Ensaio de compressão de corpos-de-prova cilíndricos. Rio de Janeiro: ABNT; 1994.

17 Tiguman MP. Estudo comparativo entre métodos de quantificação de tenacidade usando concreto reforçado com macrofibras de polipropileno [dissertação]. São Paulo: Escola Politécnica, Universidade de São Paulo; 2004.

Recebido em: 27 Jan. 2017

Aceito em: 13 Mar. 2017 